\title{
ORGANIZAÇÃO DIDÁTICO-METODOLÓGICA DE AULAS DE EDUCAÇÃO FÍSICA NO ENSINO FUNDAMENTAL: ESTUDO DE CASO
}

Francisco Celso Lima da Silva, Universidade do Estado de Santa Catarina - UDESC, Florianópolis, Santa Catarina - Brasil

Gelcemar Oliveira Farias, Universidade do Estado de Santa Catarina - UDESC, Florianópolis, Santa Catarina - Brasil

Marilia Garcia Pinto, Universidade Federal de Santa Catarina- UFSC, Florianópolis, Santa Catarina - Brasil

William Neves Salles, Universidade Federal de Santa Catarina - UFSC, Florianópolis, Santa Catarina - Brasil

\section{RESUMO}

O objetivo do estudo foi analisar a organização didática e metodológica de aulas de Educação Física nos anos iniciais do ensino fundamental. A partir de abordagem descritivo-exploratória, utilizou-se matriz de observação para analisar dez intervenções de uma professora com formação em Educação Física para 18 alunos pertencentes ao terceiro ano do ensino fundamental de uma escola pública estadual de Florianópolis. Os resultados indicaram que a organização didático-metodológica das aulas observadas foi estruturada da seguinte maneira: rito de início da aula (trajeto para a aula, início da aula, atividade inicial); atividades intermediárias; explicação das atividades propostas; e o final da aula. A professora, ao mesmo tempo em que se revelou participativa, explicou com clareza o objetivo das atividades. Frequentemente, houve a separação das crianças por sexo. A realização de estudos com foco no fazer didático e pedagógico de professores de Educação Física escolar ainda deve ser profundamente investigada, a fim de contribuir com o processo de desenvolvimento profissional do professor.

Palavras-Chave: Educação Física; Aula; Didática; Escola. 


\title{
DIDACTIC-METHODOLOGICAL ORGANIZATION OF PHYSICAL EDUCATION CLASSES IN BASIC EDUCATION: CASE STUDY
}

\begin{abstract}
The aim of the study was to analyze the methodological and didactic organization of Physical Education classes in the early years of elementary school. From descriptive and exploratory approach, an observation matrix was used to analyze ten interventions from a teacher with training in Physical Education to 18 students belonging to the third year of elementary school in a state school in Florianópolis. The results indicated that the didactic and methodological organization of the observed classes was structured as follows: rite of class start (ride to class, beginning of class, initial activity); intermediate activities; explanation of the proposed activities; and the end of the class. The teacher, while revealed herself as an active participant, clearly explained the purpose of the activities. Often, there was the separation of children by sex. The studies with a focus on the Physical Education teacher's didactic-pedagogic work at school should still be deeply investigated in order to contribute to the process of teacher professional development.
\end{abstract}

Key-Words: Physical Education; Class; Didactic; School.

\section{ORGANIZACIÓN DIDÁCTICO-METODOLÓGICA DE AULAS DE EDUCACIÓN FÍSICA EN LA EDUCACIÓN BÁSICA: ESTUDIO DE CASO}

\section{RESUMEN}

El objetivo del estudio fue analizar la organización metodológica y didáctica de clases de Educación Física en los primeros años de la escuela primaria. A partir de enfoque descriptivo y exploratorio, se utilizó matriz de observación para analizar diez intervenciones de una profesora con formación en Educación Física para 18 alumnos pertenecientes al tercer año de la educación primaria en una escuela pública de Florianópolis. Los resultados indicaron que la organización didáctico-metodológica de las clases observadas se estructuró de la siguiente manera: rito del inicio de clases (camino a clase, inicio de la clase, actividad inicial); actividades intermedias; explicación de las actividades propuestas; y el final de la clase. El maestro, mientras que si reveló participativa, explicó claramente el propósito de las actividades. A menudo, se produjo la separación de los niños por sexo. La realización de estudios con enfoque en el hacer didáctico y pedagógico de profesores de Educación Física de la escuela debe aún ser profundamente investigada con el fin de contribuir al proceso de desarrollo profesional docente.

Palabras-Clave: Educación Física; Clase; Enseñanza; Escuela. 


\section{INTRODUÇÃO}

O estabelecimento de reflexões sobre a realidade da Educação Física no Brasil é de suma importância para o profissional da área, uma vez que, para proporcionar uma aula atrativa para os alunos, é necessário que o professor domine competências e métodos específicos para facilitar a aprendizagem dos alunos.

A Educação Física escolar brasileira vem sendo desenvolvida, ao longo dos anos, por meio de métodos trazidos de outros países, especialmente do continente europeu. Juntamente com os métodos, diversas foram as concepções provindas do exterior, com destaque para as concepções Higienista, Militarista, Esportivista e Recriacionista. ${ }^{1}$

No fim da década de 1970, passam a surgir novas concepções, todas elas tendo em comum a tentativa de romper com o modelo mecanicista, esportivista e tradicional. Dentre elas, as que mais se destacaram são: Psicomotricidade, Desenvolvimentista, Construtivista, Crítico-superadora, Crítico-emancipatória, Saúde renovada e Parâmetros Curriculares Nacionais, ou PCN's. ${ }^{2}$ Embora possuam enfoques diferenciados, essas abordagens possuem o mesmo intuito, que é o de buscar promover a ampliação da concepção de ser humano por meio da integração das dimensões física, psíquica e social. ${ }^{3}$

A Educação Física está prevista, atualmente, na Lei de Diretrizes e Bases da Educação Nacional (LDB) como um componente curricular da Educação Básica. Desse modo, ela deve estar associada à proposta pedagógica da escola, ajustando-se às faixas etárias e às condições da população escolar. Sua função primordial está relacionada à promoção de oportunidades de experimentação, reflexão/problematização e recriação de diversas práticas corporais presentes na cultura de movimento. ${ }^{4}$

A didática auxilia o professor a melhor compreender os objetivos da instrução e da educação, a desempenhar métodos e estratégias específicas para o ensino dos conteúdos e a compreender a ligação que possui o conteúdo, o ensino e a atividade dos alunos. ${ }^{5}$ Os procedimentos didáticos de um plano curricular não devem se orientar apenas no conteúdo e métodos de ensino do qual derivam, mas sim estimular a interação educativa com enfoque nas relações pessoais, especialmente a comunicação humana. ${ }^{6}$ 
A organização de um programa de Educação Física escolar e a seleção dos conteúdos a serem desenvolvidos são questões de suma importância para a qualidade do processo de ensino aprendizagem. Pode-se dizer que o programa é a base da disciplina, e elementos principais são: o conhecimento de que trata a disciplina, sistematizado e distribuído, que geralmente se denomina de conteúdos de ensino; o tempo pedagogicamente necessário para o processo de assimilação do conhecimento; e os procedimentos didáticometodológicos para ensiná-lo. ${ }^{4}$

Considerando o exposto, o presente estudo apresenta como objetivo analisar a organização didática e metodológica das aulas de Educação Física nos anos iniciais do ensino fundamental.

\section{PROCEDIMENTOS METODOLÓGICOS}

O estudo se caracteriza como descritivo-exploratório. ${ }^{7}$ Os participantes foram uma professora com formação em Educação Física, além de 18 alunos pertencentes ao terceiro ano do Ensino Fundamental de uma escola pública estadual de Florianópolis. A professora, com 49 anos de idade, possui formação inicial em Licenciatura Ampliada em Educação Física, concluída em 1986, atuando no magistério desde 1984. Os alunos, por sua vez, tinham idades entre 9 a 12 anos.

O projeto foi submetido ao Comitê de Ética em Pesquisa com Seres Humanos da Universidade do Estado de Santa Catarina, sendo posteriormente aprovado (parecer 474.502). Ressalta-se que a participação da professora e dos alunos ocorreu após a leitura e concordância com o Termo Consentimento Livre e Esclarecido (TCLE). De modo a obter a autorização dos alunos para participar do estudo, o TCLE foi encaminhado para que os pais ou responsáveis assinassem antes da coleta de dados.

O instrumento utilizado para coleta das informações foi uma matriz de observação diretamente relacionada à aula de Educação Física. Nesse sentido, foram observadas dez aulas de Educação Física, em dias consecutivos, sendo interrompidas somente em função 
de atividades já planejadas no calendário escolar ou devido à ausência da professora de Educação Física.

Para o processo de análise dos dados, foi utilizada a técnica da análise de conteúdo ${ }^{8}$ referente aos dados oriundos das observações. Desta maneira, as anotações foram categorizadas a posteriori, de acordo com a estrutura organizativa proposta pela professora, resultando nas seguintes unidades de análise: momento de início da aula (trajeto para a aula, início da aula, primeira atividade); atividades intermediárias; explicação das atividades propostas; parte final da aula.

\section{RESULTADOS}

As informações obtidas buscaram melhor compreender como a aula de Educação Física pode ser pensada e repensada no contexto escolar, de modo a trazer com mais clareza a proposta pedagógica de uma professora no que se refere ao tempo e ao espaço da aula de Educação Física, à organização didática e à concepção da estrutura da aula de Educação Física.

Nas aulas observadas, pode-se notar acompanhamento da professora aos alunos, ação rotineira que foi percebida em todas as aulas. Nesse sentido, a professora sempre buscava os alunos em sala, sendo que ora a explicação das atividades se dava neste momento e ora quando já estavam no local destinado ao desenvolvimento das aulas.

A ordenação da fila para iniciar o trajeto para a aula era prática constante. Neste momento, os alunos eram separados por sexo e encaminhados para a quadra ou pátio coberto. Em uma das observações realizadas, no decorrer da caminhada para o local da aula, a professora fez uma pausa para explanar sobre as atividades que seriam desenvolvidas no dia.

$\mathrm{Na}$ parte inicial da aula, a professora constantemente realizava o aquecimento, caracterizado por alongamentos e atividades de corrida. Esta ação era marcada por corridas ao redor da quadra e pela quadra, ou por brincadeiras cuja locomoção, também por meio da corrida, eram as mais destacadas. Materiais como cones, cordas e colchonetes eram utilizados no intuito de sistematizar as dinâmicas de aquecimento propostas pela Conexões: revista da Faculdade de Educação Física da UNICAMP, Campinas, v. 13, n. 3, p. 231-241, jul./set. 2015. ISSN: $1983-9030$ 
professora. Em todas as atividades propostas, a professora estava inserida no contexto, realizando as atividades juntamente com os alunos.

No que se referem às atividades intermediárias das aulas, as mesmas caracterizavam-se fundamentalmente por sua baixa complexidade, envolvendo elementos da equilíbrio, flexibilidade, corrida, atenção e agilidade. Neste sentido, em quase todas as aulas a professora propôs aos alunos a queimada e atividades que são variações do pega-pega.

Um fato que merece destaque está pautado nas explicações enunciadas pela professora no decorrer da aula. Além da explicação enfática, demonstrava primeiramente através de gestos o que estava sendo solicitado aos alunos. Como resultado, o sucesso dos alunos se tornava rotineiro, pois essa ação didática fator motivava e incentivava os alunos para a prática da atividade proposta, proporcionando a ampliação dos saberes dos alunos no que tange aos aspectos motores, cognitivos, sociais e culturais.

Durante as aulas observadas, foi perceptível o engajamento e competência da professora para repassar aos alunos, através da explicação, as atividades propostas na parte intermediária das aulas. A professora sempre se manteve preocupada com a compreensão e com o desenvolvimento correto dos exercícios sugeridos.

No que se refere ao aspecto pedagógico, a professora demonstrou total domínio da turma, agindo com firmeza e personalidade, além de demonstrar conhecimento do conteúdo abordado nas aulas. Sempre aberta para novos questionamentos, a professora conversava com os alunos durante a execução das atividades, incentivando e motivando os escolares a participarem ativamente e de forma organizada.

De modo geral, as aulas observadas foram finalizadas com brincadeiras que contavam com a participação de todos os alunos e tinham o intuito de deixá-los mais interessados nas aulas em sala. A atividade proposta pela professora, na maioria das ocasiões, foi o "Passa Anel", que possibilitava aos alunos o senso de organização, disciplina e respeito pelo colega. Após o término da atividade, os alunos se dirigiam em fila até o bebedouro, ao banheiro e, posteriormente à sala de aula, onde a professora, em algumas ocasiões, realizava o feedback, ressaltando o comportamento e a atitude da turma naquele dia. 


\section{DISCUSSÃO}

No contexto escolar, a aula de Educação Física representa um estado de ação, movimento, aprendizagem, relações interpessoais e socialização entre os pares, pois a infância é caracterizada por concentrar as aquisições fundamentais para o restante do desenvolvimento humano, pois é nessa etapa da vida que o indivíduo forma a base motora para a realização de movimentos mais complexos futuramente. ${ }^{9}$ Neste momento é importante que a criança tenha um bom acompanhamento no seu desenvolvimento físico, cognitivo e psicossocial.

A intervenção dos professores de Educação Física deve ser constantemente refletida, no sentido de que a aula tenha significado para a aprendizagem do aluno e que a mesma seja contemplada por competências, que irão transpassar a vida escolar. Sabe-se que um dos recursos pedagógicos mais importantes e particular, utilizados nas aulas de Educação Física, são as próprias atividades corporais provenientes da cultura da criança, ${ }^{10}$ as atividades relacionadas à Educação Física se compõem como elementos fundamentais na vivência dos alunos, em interação com valores e conceitos do contexto sociocultural, que possibilitam a comunicação por meio da linguagem corporal. ${ }^{11-12}$

$\mathrm{Na}$ parte prática e inicial da aula, a professora investigada no presente estudo constantemente realizava o aquecimento, caracterizado por alongamentos e exercícios de corrida. Algumas das atividades eram organizadas de maneira que os alunos fossem separados por sexo. Tal ação faz refletir sobre a contrariedade que existe em separar os alunos desta maneira, justamente no local onde a socialização e a igualdade são estimuladas. Os meninos e as meninas separadas por gênero na escola revela a superioridade do primeiro grupo em relação ao segundo, logo no tempo de diversidade e inclusão o qual preconiza os documentos oficiais da legislação, não se deve aceitar tal separação. $^{13}$ 
No período observado, a professora foi muito participativa das atividades preliminares, chegando até mesmo a realizá-las integralmente ao lado de seus alunos. As explicações, muito detalhadas, clarificavam aos alunos o objetivo a ser atingido e a organização necessária para o sucesso da proposta. Dentre as principais propostas, destacaram-se as brincadeiras de baixa complexidade.

Ressalta-se que uma das principais qualidades do profissional de Educação Física é a criação de vínculos positivos com os alunos, bem como a participação ativa e a criatividade no planejamento e desenvolvimento da aula. ${ }^{14}$ No que tange às atividades de baixa complexidade, acredita-se que, além delas, existam outras propostas que devam ser abordadas nas aulas nos anos iniciais do ensino fundamental de maneira a ampliar as possibilidades da criança, com destaque para atividades pré-desportivas; atividades de autocontrole; e atividades rítmicas. ${ }^{15}$

A explicação se torna importante para que o aluno entenda o significado da ação motora e consiga realizá-la de forma mais eficiente. Frequentemente, observa-se em aulas de Educação Física a execução de ações motoras de forma equivocada pelos alunos, pois não entenderam o enunciado da tarefa. Assim, torna-se imprescindível que a mensagem chegue ao aluno de forma clara e concisa, fato que irá facilitar a aprendizagem e compreensão do educando. Tal estratégia vem de encontro a um estudo que menciona que para o ser humano o importante não é apenas fazer, mas sim tomar consciência daquilo que faz. ${ }^{10}$ Fica claro então, que estas crianças que passaram anos anteriores formando estruturas motoras, afetivas, sociais e cognitivas, ao compreender aquilo que lhe está sendo proposto, produzem o estímulo, o desejo e a necessidade de mais conhecimento através das aulas de Educação Física.

A finalização da aula de Educação Física tem por objetivo trazer uma atividade que proporcione, fundamentalmente, reflexão sobre a prática realizada. Quando esta etapa não é realizada, os alunos continuam agitados e empolgados, e normalmente não conseguem perceber a importância da atividade realizada para seu desenvolvimento enquanto ser humano. ${ }^{16}$ Neste sentido, uma boa aula de Educação Física deve se preocupar em realizar uma dinâmica que possibilite e acentue o aprendizado de conhecimentos específicos da Educação Física, assim como os aspectos da realidade social que estão por trás dessas práticas. ${ }^{4}$

Conexões: revista da Faculdade de Educação Física da UNICAMP, Campinas, v. 13, n. 3, p. 231-241, jul./set. 2015. ISSN: $1983-9030$ 


\section{CONSIDERAÇÕES FINAIS}

Realizar uma aula didática e metodologicamente coerente, que perpasse conhecimento aos alunos e que estes estejam envolvidos e motivados a participar, de modo a colaborarem para o crescimento próprio e coletivo, é um dos principais desafios para os profissionais da área de Educação Física. Neste cenário, ao final deste estudo, foi possível verificar as práticas didático-metodológicas que a professora utilizou na organização das aulas observadas.

As evidências identificaram a existência de uma organização sistematizada pela professora. Tal sistematização baseia-se nos seguintes pontos: rito de início da aula (trajeto para a aula, início da aula, atividade inicial), as atividades intermediárias, explicação das atividades propostas e o final da aula.

Através das observações, foi visível a separação dos tempos e espaços destinados à aula de Educação Física, percebendo de forma clara seu início, meio e fim. Em suma, o início da aula era composto pelo deslocamento dos alunos em fila, da sala de aula até o ambiente de realização das atividades, contando sempre com uma breve explicação sobre os exercícios que seriam desenvolvidos no dia. $\mathrm{O}$ aquecimento e alongamento também aconteciam neste período.

Após o início, as atividades intermediárias buscavam explorar a percepção de espaço, equilíbrio, força e agilidade dos escolares, por meio de brincadeiras relacionadas à queimada e variações do pega-pega, que contavam com a exemplificação da professora antes da execução, de fato, das atividades.

O momento final era caracterizado por uma brincadeira que possuía como objetivo o retorno à tranquilidade, comumente chamada de atividades de volta à calma. Geralmente a professora utilizava a brincadeira de "Passa o Anel" e, ao finalizar, permitia que os alunos se encaminhassem ao bebedouro e banheiro antes de entrarem em sala. Quando necessário, a professora realizava nesta etapa, comentários sobre a aula e sobre o comportamento dos alunos. 
Cabe destacar que durante a aula, a professora buscava constantemente que a mensagem passada aos alunos fosse transmitida de forma clara e objetiva, com o intuito de aprimorar a aprendizagem motora e adquirir e reter conhecimento.

Sabe-se que a Educação Física, embora já tenha sido investigada diversas vezes e percebido a falta de métodos para a diversificação da aula, um professor comprometido com a excelência do ensino ainda traz novos elementos para garantir a aprendizagem dos seus alunos. Por isso, a realização de estudos com foco no fazer didático e pedagógico de professores de Educação Física escolar ainda deve ser profundamente investigada, a fim de contribuir com o processo de desenvolvimento profissional do professor.

\section{REFERÊNCIAS}

${ }^{1}$ XAVIER NETO, L. P.; ASSUNÇÃO, J. R. Educação Física (saiba mais). Rio de Janeiro: Unit, 2005.

${ }^{2}$ DARIDO, S. C.; RANGEL, I. C. A. Educação Física na escola: implicações para a prática pedagógica. Rio de Janeiro: Guanabara Koogan, 2005.

${ }^{3}$ DARIDO, S. C. Educação Física na escola: questões e reflexões. Rio de Janeiro: Guanabara Koogan, 2003.

${ }^{4}$ COLETIVO DE AUTORES. Metodologia do ensino de Educação Física. São Paulo: Cortez, 1992.

${ }^{5}$ GHIRALDELLI JR., P. Educação Física progressista: a pedagogia crítico-social dos conteúdos e a Educação Física brasileira. 10. ed. São Paulo: Loyola, 2007.

${ }^{6}$ MARQUES, M. O. Pedagogia: a ciência do educador. Ijuí: Ed. da Unijuí, 1990.

${ }^{7}$ GIL, A. C. Como elaborar projetos de pesquisa. 5. ed. São Paulo: Atlas, 2010.

Conexões: revista da Faculdade de Educação Física da UNICAMP, Campinas, v. 13, n. 3, p. 231-241, jul./set. 2015. ISSN: $1983-9030$ 
${ }^{8}$ BARDIN, L. Análise de conteúdo. São Paulo: Edições 70, 2011.

${ }^{9}$ PEREZ GALLARDO, J. S. Educação Física escolar: do berçário ao ensino médio. Rio de Janeiro: Lucerna, 2003.

${ }^{10}$ FREIRE, J. B. Educação de corpo inteiro: teoria e prática da Educação Física. São Paulo: Scipione, 2003.

${ }^{11}$ CAPARROZ, F. E.; BRACHT, V. O tempo e o lugar de uma didática da Educação Física. Revista Brasileira de Ciências do Esporte, Campinas, v. 28, n. 2, p.21-37, 2007.

${ }^{12}$ MATTOS, M. G.; NEIRA, M. G. Educação Física infantil: construindo o conhecimento na escola. São Paulo: Phorte, 2002.

${ }^{13}$ FREIRE, J. B. Educação de corpo inteiro: teoria e prática da Educação Física. São Paulo: Scipione, 1989.

${ }^{14}$ FARIA JR., A. G. Introdução à didática de Educação Física. Brasília: Divisão de Educação Física do MEC, 1986.

${ }^{15}$ KREBS, R. J.; RAMALHO, M. H. S. Planejamento curricular para educação básica: Educação Física: caderno pedagógico. Florianópolis: IOESC, 2011.

${ }^{16}$ PADILHA, S. L.; PIETA, S. A. A influência da atividade de volta à calma para a melhoria do aprendizado em crianças do ensino fundamental. Paraná: UNICS. Disponível em: http://www.educadores.diaadia.pr.gov.br/modules/mydownloads_01/singlefile.php?cid=36 $\underline{\& l i d=6291>}$. Acesso em: 22 set.2013.

Recebido em: 9 jun. 2015

Aceito em: 30 ago. 2015

Contato: mari_garcia@yahoo.com.br

Conexões: revista da Faculdade de Educação Física da UNICAMP, Campinas, v. 13, n. 3, p. 231-241, jul./set. 2015. ISSN: 1983-9030 